\title{
Infestation indices and characterization of injuries of Drosophila suzukii Matsumura (Diptera: Drosophilidae) in Barbados cherry
}

\author{
Léo Rodrigo Ferreira Louzeiro ${ }^{\bowtie 1}{ }^{-}$, Miguel Francisco Souza-Filho' ${ }^{1}$, Adalton Raga ${ }^{1}$, \\ Carla A. Bulgarelli1@ \& Louis Bernard Klaczko-
}

1. Instituto Biológico. Economic Entomology Laboratory, Campinas, SP, Brazil. 2. UNICAMP. Inst. Biologia. Department of Genetics, Evolution, Microbiology and Immunology, Campinas, SP, Brazil.

EntomoBrasilis 13: e898 (2020)

\section{Edited by:}

Marliton Rocha Barreto

Article History:

Received: 11.ii.2020

Accepted: 26.iv.2020

Published: 25.vi.2020

\section{Corresponding author:}

Léo Rodrigo Ferreira Louzeiro

\} leo.rfl@hotmail.com

\section{Funding agencies:}

4 Coordenação de Aperfeiçoamento de Pessoal de Nível Superior - Brazil (CAPES); Fundação de Amparo à Pesquisa do Estado de São Paulo (FAPESP); Cons. Nac. Desenvolvimento Científico e Tecnológico $(C N P q)$.

\begin{abstract}
Females of Drosophila suzukii Matsumura (Diptera: Drosophilidae) have a serrated ovipositor that causes severe physical damage to soft fruit. This behaviour results in the early ripening and accelerated rotting of infested fruit. In addition, feeding by larvae softens of the fruit peel, causing in a depreciation in commercial value. In this study, results of infestation indices, pupal viability, egg-adult period, degradation time of infested fruit, and description of physical injuries caused by oviposition and larval feeding of D. suzukii in Barbados cherries (Malpighia emarginata DC., Malpighiaceae) are described. Overall, our results and discussion contribute to the understanding of the status of $D$. suzukii as an insect pest of the Barbados cherry.
\end{abstract}

Keywords: Acerola; Depreciated fruit; Fruit damage; Insect pest; Spotted-wing drosophila
D) rosophila suzukii Matsumura (Diptera: Drosophilidae) is an important insect pest in fruit orchards around the world. An invasive species, it probably originating in Asia and has spread to North America, South America and Europe (Deprá et al. 2014; Asplen et al. 2015). It is a polyphagous fly that prefers to oviposit on ripe, red, soft fruit (LeE et al. 2011, 2015; DiePENBROck et al. 2016).

Drosophila suzukii is also known as spotted-wing drosophila due to the males characteristic dark spot on the edge of each wing. Females do not have wing spots. However, they have a serrated ovipositor that allows them to infest and physically damage fruit. These male and female characteristics distinguish D. suzukii from other drosophilids (WALSH et al. 2011; Miller et al. 2017; NiKolouli et al. 2018).

The importance of $D$. suzukii is due to the damage caused by females in fruit production. Using their serrated ovipositor, females penetrate the peel of soft fruit, resulting in a minor injury to the peel. A few days after oviposition, the larvae hatch and begin to feed on the fruit pulp. The injury caused by oviposition opens a door for attack by other insects, fungal infections and bacterial diseases. In addition, feeding by the larvae results in soft, brown, sunken spots on the fruit (WALSH et al. 2011). This causes premature depreciation of fruit, resulting in yield losses and economic damage to the fresh fruit chain (Goodhue et al. 2011; WaLSH et al. 2011).
The first reports of D. suzukii in Brazil were in 2013 in the states of Santa Catarina and Rio Grande do Sul, Brazil (Deprá et al. 2014). After its detection, D. suzukii managed to disperse through several Brazilian regions (ANDREAzzA et al. 2017; ZANUNCIO-JUNIOR et al. 2018), probably through the transportation of infested fruit intended for commercial sale (VILELA \& MoRI 2014). In Brazil, D. suzukii has been characterized as an insect pest mainly targeting red fruit such as strawberries [Fragaria $\times$ ananassa (Duchesne ex Weston) Duchesne ex Rozier] (SANtos 2014; Andreazza et al. 2016), with potential damage to several other fruit crops (Benito et al. 2016; Wollmann et al. 2019).

The Barbados cherry (Malpighia emarginata DC., Malpighiaceae) is a fruit of economic importance in Brazil. In 2017 its production reached 142,992 metric tons in 7,724 ha (IBGE 2017). The fruit is soft and reddish when ripe. The Barbados cherry is a natural host of $D$. suzukii in the field. Potentially $D$. suzukii is a primary pest for this fruit crop (LouzeIro et al. 2019). Considering the impact of $D$. suzukii as a fruit pest, and its potential be a pest for a variety crops, our objectives were to evaluate the infestation of the Barbados cherry with respect to the duration of exposure to mature D. suzukii females and to characterise the injuries caused by infestation in laboratory.

Barbados cherry fruit were collected in the municipality of Mogi Mirim, São Paulo state, Brazil (22³1'13.48" S 
$47^{\circ} 00^{\prime} 36.83^{\prime \prime} \mathrm{W}$ ) in June 2019. Fruit that were reddish in colour were collected directly from the trees and were immediately brought to the Economic Entomology Laboratory, Instituto Biológico, where they were washed in sodium hypochlorite solution $(0.5 \% \mathrm{v} / \mathrm{v})$ and allowed to dry. The females used in this study came from the Drosophila Stock Center at the Departamento de Genética, Evolução, Microbiologia e Imunologia, Instituto de Biologia, UNICAMP, and were raised on an artificial diet based on molasses and cornmeal (FreIREMAIA \& PAVAN 1949). Fruit were deposited individually into 50 $\mathrm{mL}$ glass tubes containing a moistened cotton pad in the base. Ten 16-day-old $D$. suzukii females were inserted into each tube and the tubes were sealed with cotton balls. After infestation, individual fruit were placed in $50 \mathrm{~mL}$ plastic pots with a vermiculite layer at the inferior base. The plastic pots were sealed with voile fabric and fastened with an elastic. The fruit were kept in a room at $23 \pm 0.5^{\circ} \mathrm{C}$ and $65 \pm 5 \%$ relative humidity during storage and the infestation experiments. The infestation experiments were performed to evaluate infestation indices (puparia/fruit and puparia/gram of fruit) during the infestation period and characterise the injuries caused by oviposition and larval feeding by $D$. suzukii. The infestation indices were evaluated after 12, 24 and $48 \mathrm{~h}$ of exposure to $D$. suzukii. Eight fruit were used at each time of exposure, totalling 24 fruit; each one was considered a replica. Twenty days after infestation, puparia and adults of $D$. suzukii were counted. To characterise infestation injuries, we used six infested fruit that were subjected to $24 \mathrm{~h}$ of exposure. The injuries caused by oviposition were recorded using a camera (Canon - PowerShot A650 IS) coupled with a stereoscope microscope (Zeiss-Stemi 2000-C) 24 h after infestation. Injuries caused by larval feeding were recorded every two days. Percentage of pupal viability was calculated by the formula: (number of adults/number of puparia) $\times 100$ in each replica. The relationships between fruit exposure time versus the values of infestation indices (puparia/ fruit and puparia/gram of fruit) and between puparia per fruit versus percentage of pupal viability were analysed by Pearson's correlation at $95 \%$ significance ( $p$-value $\leq 0.05$ ) using SAS University Edition software (Version 3.8) (SAS Enterprise Miner 13.1. SAS Institute Inc., Cary, NC.).

Infestation indices and pupal viability of $D$. suzukii in Barbados cherries varied with fruit exposure time (Table 1). The highest infestation indices were 70.0 puparia per fruit and 14.6 puparia per gram observed in the shortest exposure time (12 h). A weak, negative and non-significant correlation was detected between exposure time and puparia per fruit $(r=$ -0.2399 , d.f. $=23, p$-value $=0.2588$, and between exposure time and puparia per gram $(r=-0.1982$, d.f. $=23, p$-value $=$ $0.3532)$. The highest pupal viability occurred in the shortest exposure time (12h), when the infestation indices were higher than other times. A strong, positive and significant correlation was observed between puparia per fruit and pupal viability $(r=0.7129$, d.f. $=23, p$-value $<0.0001)$. The egg-adult period ranged from 13 to 16 days. The shortest egg-adult period occurred in the highest infestation index (Table 1). The characterisation of the infestation of $D$. suzukii in Barbados cherries showed that a fruit is susceptible to multiple punctures (Figure 1A). The oviposition of D. suzukii causes a circular and/or semicircular wound approximately 0.2-0.3 $\mathrm{mm}$ in diameter where the female inserts eggs into the fruit (Figure 1B). The ovipositions may be near to each other (Figure 1C), or far from each other (Figure 1D). Peeling of the skin at the oviposition site was observed and fruit degradation progressed as the larvae developed. During the larval feeding period, the pulp of the fruit softened, accompanied by a change in the colour of the peel at the attack site. Five days after the initial infestation, the fruit were completely depreciated (Figure 1E).

In this study, in contrast to our initial hypothesis, the infestation indices of $D$. suzukii were not directly proportional to the fruit exposure time. It is probable that the maximum infestation level a unique Barbados cherry can withstand was reached in the first few hours of infestation. Females of D. suzukii may have avoided oviposition once they perceived that the fruit could collapse and would not provide enough substrate for larval development. Drosophila suzukii likely leaves host chemical markers, as do many other insects (Roitberg \& Prokopy 1987). Some studies have reported that the number of ovipositions of $D$. suzukii vary, mainly due to host preference, maturation stage and ${ }^{\circ}$ Brix of the fruit (LEE et al. 2011; Walsh et al. 2011; DiepenBrock et al. 2016).

Based on the infestation indices, pupal viability and short eggadult period, the Barbados cherry is a substrate favourable for the development of $D$. suzukii immatures. This evidence is based on positive and significant correlation between puparia per fruit and pupal viability. Probably the physicochemical characteristics of the Barbados cherry, such as pH (ranging from 3.0 to 3.5), maturity index (total soluble solids/titratable acidity) (from 5.0 to 5.8) and vitamins (SANTOS et al. 2012; SAGAR et al. 2013) contributed to the high developmental rates of immature $D$. suzukii.

Even with a few hours of fruit exposure, the fly can perform multiple ovipositions and achieve good egg-adult development. Infestation conditions in the laboratory, with 10 females per fruit, do not correspond to field infestations, which generally range from one to five puparia per fruit (LouzeIRo et al. 2019), but demonstrate the host potential of Barbados cherry and its influence on the demography. This preliminary study demonstrates that under high populational pressure (10 female D. suzukii) the Barbados cherry can endure high levels of infestation. In backyards, isolated crops or mixed orchards, Barbados cherries may sustain the $D$. suzukii population, especially in tropical regions where some crops may be harvested all year long. As a polyphagous fly D. suzukii can use successive host (DiePENBrock et al. 2016; Wollmann et al. 2019) to maintain its population in the field throughout the year. This increases the risk of damage to commercial fruit orchards.

The puncture, oviposition and larval feeding of $D$. suzukii inflict significant injuries on Barbados cherries. This can jeopardise their production and commercial sale due to further infection by pathogens that contribute to fruit rot (WALSH et al. 2011), as well as the total depreciation of the fruit in a few days due to larval feeding. Our results help expand the understanding of the potential pest status of $D$. suzukii for the Barbados cherry

Table 1. Mean values ( \pm standard error) of Barbados cherries (length, diameter, weight) tested under laboratory infestation $(\mathrm{N}=8$ per treatment), infestation indices, pupal viability, and life cycle of Drosophila suzukii (Drosophilidae) after different durations of fruit exposure.

\begin{tabular}{|c|c|c|c|c|c|c|c|}
\hline \multirow{2}{*}{$\begin{array}{c}\text { Time } \\
\text { (h) }\end{array}$} & Length (cm) & Diameter (cm) & Weight (g) & $\begin{array}{l}\text { Puparia per } \\
\text { fruit }\end{array}$ & Puparia per g & $\begin{array}{c}\text { Pupal viability } \\
(\%)\end{array}$ & $\begin{array}{l}\text { Egg-adult period } \\
\text { (day) }\end{array}$ \\
\hline & Mean ( \pm SE) & Mean ( \pm SE) & Mean ( \pm SE) & Mean ( \pm SE) & Mean ( \pm SE) & Mean ( \pm SE) & Mean $( \pm$ SE) \\
\hline 12 & $1.8( \pm 0.03)$ & $2.1( \pm 0.05)$ & $4.4( \pm 0.28)$ & $39.5( \pm 5.9)$ & $9.1( \pm 1.3)$ & $90.6( \pm 2.6)$ & $14.2( \pm 0.3)$ \\
\hline 24 & $1.6( \pm 0.06)$ & $1.8( \pm 0.06)$ & $3.3( \pm 0.30)$ & $18.7( \pm 7.3)$ & $4.9( \pm 1.7)$ & $56.0( \pm 14.2)$ & $14.6( \pm 0.4)$ \\
\hline 48 & $1.7( \pm 0.07)$ & $1.8( \pm 0.07)$ & $3.4( \pm 0.50)$ & $24.0( \pm 8.2)$ & $6.1( \pm 1.8)$ & $75.4( \pm 12.3)$ & $15.5( \pm 0.1)$ \\
\hline
\end{tabular}




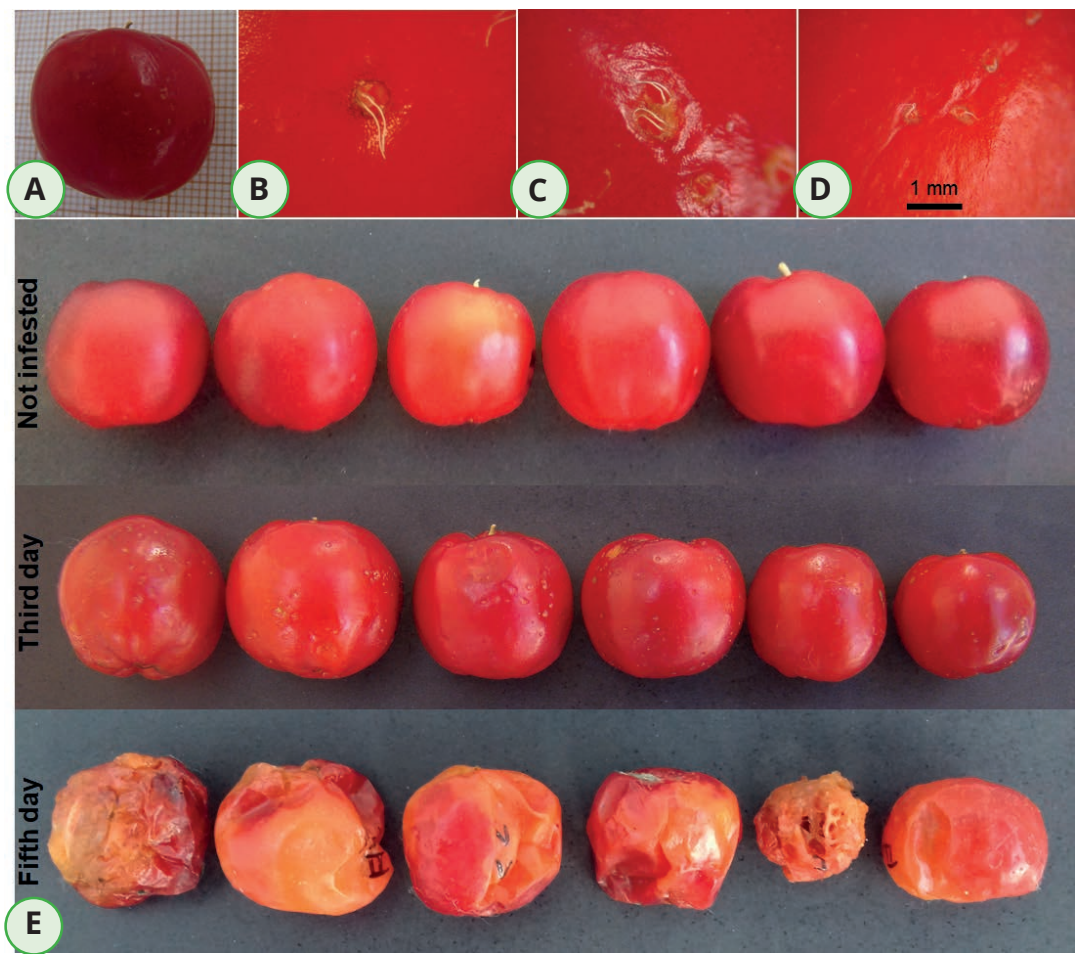

Figure 1. Multiple ovipositions of Drosophila suzukii (Drosophilidae) (A), injury of puncture and oviposition (B), eggs close to each other (C), eggs far from each other (D), and ovipositions and evolution of Barbados cherry degradation due to larval development (E).

crop. Infestation indices, pupal viability and egg-adult period can help in studies of biology, ecology and the relationship between fly/host fruit. Moreover, characterisation of the injuries caused by $D$. suzukii infestation differs from that of other frugivorous flies that infest Barbados cherries. Further, basic and applied studies on the biology, ecology and behaviour of $D$. suzukii in fruit orchards are necessary for a better understanding of its status a fruit pest.

In conclusion, we show for the first time that $D$. suzukii infestation indices are not correlated with the fruit's exposure time to females. To detect any correlation, we suggest the study of short time intervals (hourly intervals up to 9-10 h). This result was obtained in Barbados cherries and must be further investigated to assess its generalisation to other fruit. The Barbados cherry proved to be an important host for $D$. suzukii because it allows rapid multiplication of the fly and supports high viability rates for immatures. However, the physicochemical characteristics of the host can influence the life cycle of frugivorous flies. We recommend that applied studies on this topic be presented. Drosophila suzukii has potential to be a pest in the production and commercial sale of $M$. emarginata. This potential is associated with physical injuries and rapid depreciation of the fruit caused by oviposition and larval feeding.

\section{ACKNOWLEDGEMENTS}

This study was funded in part by the Coordenação de Aperfeiçoamento de Pessoal de Nível Superior - Brazil (CAPES) [grant number 001] and Fundação de Amparo à Pesquisa do Estado de São Paulo (FAPESP).

\section{REFERENCES}

Andreazza, F, K Haddi, EE Oliveira \& JAM Ferreira, 2016. Drosophila suzukii (Diptera: Drosophilidae) arrives at Minas Gerais State, a main strawberry production region in Brazil. Florida Entomologist, 99: 796-798. DOI: https://doi.org/10.1653/024.099.0439

Andreazza, F, D Bernardi, RSS Santos, FRM Garcia, EE Oliveira, M Botton \& DE Nava, 2017. Drosophila suzukii in southern Neotropical region: current status and future perspectives. Neotropical Entomology, 46: 591-605. DOI: https://doi.org/10.1007/s13744-017-0554-7

Asplen, MK, G Anfora, A Biondi, D-S Choi, D Chu, KM Daane, P Gibert, AP Gutierrez, KA Hoelmer, WD Hutchison, R Isaacs, Z-L Jiang, Z Kárpáti, MT Kimura, M Pascual, CR Philips, C Plantamp, L Ponti, G Vétek, H Vogt, VM Walton, Y Yu, L Zappalà \& N Desneux, 2015. Invasion biology of spotted wing Drosophila (Drosophila suzukii): a global perspective and future priorities. Journal of Pest Science, 88: 469-494. DOI: https://doi.org/10.1007/s10340-015-0681-z

Benito, NP, M Lopes-da-Silva \& RSS Santos, 2016. Potential spread and economic impact of invasive Drosophila suzukii in Brazil. Pesquisa Agropecuária Brasileira, 51: 571-578. DOI: https://doi.org/10.1590/s0100-204×2016000500018

Deprá, M, JL Poppe, HJ Schmitz, DC Toni \& VLS Valente, 2014. The first records of the invasive pest Drosophila suzukii in the South American continent. Journal of Pest Science, 87: 379-383. DOI: https://doi.org/10.1007/s10340-014-0591-5

Diepenbrock, LM, KA Swoboda-Bhattarai \& HJ Burrack, 2016. Ovipositional preference, fidelity, and fitness of Drosophila suzukii in a co-occurring crop and non-crop host system. Journal of Pest Science, 89: 761-769. DOI: https://doi.org/10.1007/s10340-016-0764-5

Freire-Maia, A \& C Pavan, 1949. Introdução ao estudo da drosófila. Cultus, 1: 1-66.

Goodhue, RE, M Bolda, D Farnsworth, JC Williams \& FG Zalom, 2011. Spotted wing drosophila infestation of California strawberries and raspberries: economic analysis of potential revenue losses and control costs. Pest Management Science, 67: 1396-1402. DOI: https://doi.org/10.1002/ps.2259

IBGE, 2017. Censo Agropecuário 2017. Available in: <https://sidra.ibge.gov.br/tabela/6616>. [Accessed on: 16.vii.2019].

Lee, JC, DJ Bruck, H Curry, D Edwards, DR Haviland, RA Van Steenwyk \& BM Yorgey, 2011. The susceptibility of small fruits and cherries to the spotted-wing drosophila, Drosophila suzukii. Pest Management Science, 67: 13581367. DOI: https://doi.org/10.1002/ps.2225

Lee, JC, AJ Dreves, AM Cave, S Kawai, R Isaacs, JC Miller, S Van Timmeren \& DJ Bruck, 2015. Infestation of wild and ornamental noncrop fruits by Drosophila suzukii (Diptera: 
Drosophilidae). Annals of the Entomological Society of America, 108: 117-129. DOI: https://doi.org/10.1093/aesa/ sau014

Louzeiro, LRF, MF Souza-Filho \& CA Bulgarelli, 2019. Infestation of Malpighia emarginata (Malpighiaceae) by Drosophila suzukii (Diptera: Drosophilidae) in São Paulo State, Brazil. Florida Entomologist, 102: 645-648. DOI: https://doi.org/10.1653/024.102.0336

Miller, ME, SA Marshall \& DA Grimaldi, 2017. A review of the species of Drosophila (Diptera: Drosophilidae) and genera of Drosophilidae of Northeastern North America. Canadian Journal of Arthropod Identification, 31: 1-282. DOI: https://doi.org/10.3752/cjai.2017.31

Nikolouli, K, H Colinet, D Renault, T Enriquez, L Mouton, P Gibert, F Sassu, C Cáceres, C Stauffer, R Pereira \& K Bourtzis, 2018. Sterile insect technique and Wolbachia symbiosis as potential tools for the control of the invasive species Drosophila suzukii. Journal of Pest Science, 91: 489503. DOI: https://doi.org/10.1007/s10340-017-0944-y

Roitberg, BD \& RJ Prokopy, 1987. Insects that mark host plants. BioScience, 37: 400-406. DOI: https://doi.org/10.2307/1310563

Sagar, SB, A Kuna, TVN Padmavathi, C Kavitha, T Supraja \& C-HV Durga Rani, 2013. Estimation of physico-chemical properties, nutrient composition and antioxidant activity of acerola Malpighia emarginata DC. Journal of Research ANGRAU, 41: 97-101.

Santos, SML, AM Vasconcelos, VS Oliveira, E Clemente \& JMC Costa, 2012. Evaluation of physical and physicochemical characteristics of Malpighia emarginata DC. from the State of Ceará. International Journal of Biochemistry Research \& Review, 2: 152-163. DOI: https://doi.org/10.9734/ ijbcrr/2012/1945
Santos, RSS, 2014. Drosophila suzukii (Matsumura, 1931) (Diptera: Drosophilidae) atacando frutos de morangueiro no Brasil. Enciclopédia Biosfera, 10: 4005-4011.

Vilela, CR \& L Mori, 2014. The invasive spotted-wing Drosophila (Diptera, Drosophilidae) has been found in the city of São Paulo (Brazil). Revista Brasileira de Entomologia, 58: 371-375. DOI: https://doi.org/10.1590/s008556262014000400004

Walsh, DB, MP Bolda, RE Goodhue, AJ Dreves, J Lee, DJ Bruck, VM Walton, SD O'Neal, FG Zalom, 2011. Drosophila suzukii (Diptera: Drosophilidae): Invasive pest of ripening soft fruit expanding its geographic range and damage potential. Journal of Integrated Pest Management, 2: 1-7. DOI: https://doi.org/10.1603/ipm10010

Wollmann, J, DCH Schlesener, MS Ferreira, AP Kruger, D Bernardi, JAB Garcia, AM Nunes, MS Garcia \& FRM Garcia, 2019. Population dynamics of Drosophila suzukii (Diptera: Drosophilidae) in berry crops in Southern Brazil. Neotropical Entomology, 48: 699-705. DOI: https://doi.org/10.1007/s13744-019-00686-5

Zanuncio-Junior, JS, MJ Fornazier, F Andreazza, MP Culik, LP Mendonça, EE Oliveira, DS Martins, ML Fornazier, H Costa \& JA Ventura, 2018. Spread of two invasive flies (Diptera: Drosophilidae) infesting commercial fruits in southeastern Brazil. Florida Entomologist, 101: 522-525. DOI: https://doi.org/10.1653/024.101.0328

$$
* * * * * * * * * *
$$

\section{Suggestion citation:}

Louzeiro, LRF, MF Souza-Filho, A Raga, CA Bulgarelli \& LB Klaczko, 2020. Infestation indices and characterization of injuries of Drosophila suzukii Matsumura (Diptera: Drosophilidae) in Barbados cherry. EntomoBrasilis, 13: e898.

Available in: doi: 10.12741/ebrasilis.v13.e898

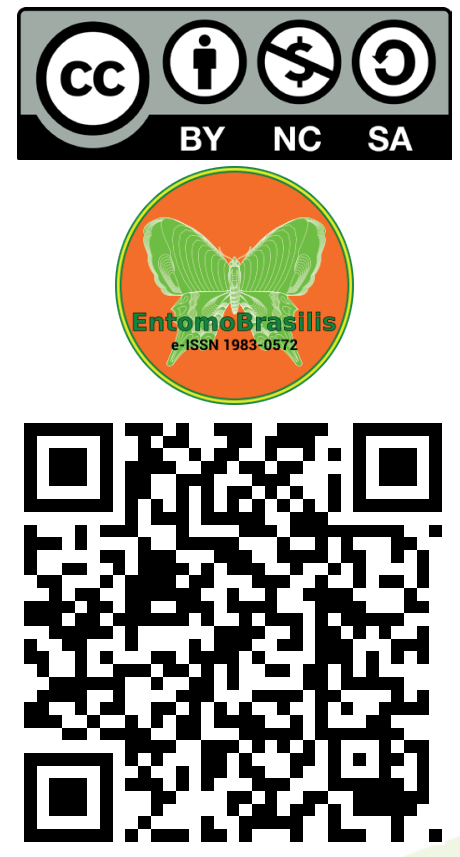

